\title{
Acessibilidade arquitetônica, deficiência física e o direito à educação
}

\author{
Architectural accessibility, physical handicap and the right \\ to education \\ Accesibilidad arquitectónica, discapacidad física y derecho \\ a la educación
}

\author{
Raphael Demóstenes Cardozo I \\ https://orcid.org/0000-0002-1983-5708 \\ Gabriela Schneider ${ }^{2}$ \\ https://orcid.org/ 0000-0002-6346-2849
}

\begin{abstract}
Resumo: Este artigo apresenta os resultados de uma pesquisa que objetiva analisar a acessibilidade arquitetônica em escolas municipais de Pinhais, no estado do Paraná, sob o viés do direito a uma educação de qualidade e das normativas já existentes. São investigadas quatro escolas, através de um roteiro de observação composto por 122 itens e entrevista com as diretoras. $O$ entorno da escola, estacionamento, entradas, salas de aula, biblioteca ou sala de leitura, laboratório de informática, refeitório, sanitários, recepção, bebedouro, espaço para prática esportiva, parque e pátio são alguns espaços e mobiliários observados. Com referência nos teóricos Crahay (2000) e Lucas (200I), foi possível identificar o mecanismo de manutenção da desigualdade (DEM), além da necessidade de discutir a adaptação dos espaços, indicadores educacionais e a ampliação da política educacional voltada à acessibilidade.
\end{abstract}

Palavras-chave: Educação. Inclusão. Acessibilidade arquitetônica.

Abstract: This paper presents the results of a study that aims to analyze architectural accessibility in municipal schools in Pinhais in the state of Paraná, under the perspective of the right to quality education and the existing regulations. Four schools are investigated through an observation script comprising 122 items and interviews with the principals. The surroundings of the school, parking area, entrances, classrooms, library or reading room, computer lab, cafeteria, restrooms, reception, drinking fountain, space for sports practice, park, and patio, are some of the spaces and furniture observed. Based on the theoretical background by Crahay (2000) and Lucas (200I), it was possible to identify the inequality maintenance mechanisms (DEM), as well as the need to discuss the adaptation of spaces, educational indicators and the broadening of an educational policy aimed at accessibility. Keywords: Education. Architectural accessibility. Inclusion.

\footnotetext{
I Mestre em Educação. E-mail: raphaeldemostenes@gmail.com.

2 Doutora em Educação. Docente do Departamento de Planejamento e Administração da Educação. E-mail: gabrielaschneider@ufpr.br.
}

Olhar de professor, Ponta Grossa, v. 24, p. I-23, e-1832I.084, 202 I.

Disponível em <https://revistas2.uepg.br/index.php/olhardeprofessor> 
Resumen: Este artículo presenta los resultados de una investigación que tiene como objetivo analizar la accesibilidad arquitectónica en las escuelas municipales de Pinhais, en el estado de Paraná, desde la perspectiva del derecho a la educación de calidad y de la normativa existente. Se investigan cuatro escuelas a través de una guía de observación, compuesta por 122 ítems, y entrevistas con las directoras. El entorno de la escuela, estacionamiento, entradas, aulas, biblioteca o sala de lectura, laboratorio de computación, comedor, baños, recepción, bebedero, espacio para práctica deportiva, parque y patio, son algunos de los espacios y equipamientos observados. Con la referencia teórica de Crahay (2000) y Lucas (200I), se pudo identificar el mecanismo de mantenimiento de la desigualdad (DEM), así como la necesidad de discutir la adecuación de los espacios, los indicadores educativos y la expansión de la política educativa orientada hacia la accesibilidad.

Palabras-clave: Educación. Inclusión. Accesibilidad arquitectónica.

\section{Introdução}

A garantia do direito à educação das pessoas com deficiência tem na Constituição Federal CF (BRASIL, 1988) e na Lei de Diretrizes e Bases da Educação Nacional - LDB (BRASIL, 1996) seus princípios balizadores, contudo, diversos documentos existem e dispõem sobre tal questão, muitos deles dando direcionamentos e diretrizes que precisam ser seguidas pelas instituições educacionais, visando primeiramente garantir o direito humano da pessoa com deficiência e, direta ou indiretamente, o direito à educação e à acessibilidade.

O conjunto dos documentos normativos e orientativos revela que, para garantir o direito à educação de qualidade, promover a dignidade, a autonomia, a segurança e o pleno desenvolvimento humano, há diversas orientações e deveres que interferem diretamente na escola, não somente no nível das condições materiais e estruturais, mas também no nível pedagógico.

Ao abranger uma perspectiva histórica e social, é possível evidenciar com tais documentos as conquistas ao longo dos anos, concretizadas pela participação cada vez mais direta e ativa dessa população na disputa por políticas públicas. Segundo Nunes (2008), no contexto da educação, os alunos com deficiência, transtornos globais de desenvolvimento e altas habilidades/superdotação, são denominados alunos com necessidades educacionais especiais (NEE) ou público-alvo da educação especial (PAEE), que perpassam todos os níveis e modalidades de ensino.

Ao verificar o número de matrículas de estudantes PAEE em nível nacional, que incluem as matrículas de alunos com deficiência, é possível aferir que, no ano de 2007, havia 313.404 alunos classificados com algum tipo de deficiência em classes comuns da educação básica; em 2020, esse número evoluiu para 1.308 .900 estudantes, o que corresponde a um acréscimo de aproximadamente $417 \%$ no período analisado. A presença de alunos com deficiência física segue esse padrão, pois no ano de 2007 havia matriculado, em classes comuns, 30.923 estudantes com deficiência física. Já no ano de 2020 , houve um salto de matrículas para 130.742 estudantes, representando um aumento de $422 \%-$ reforçando a necessidade de uma escola acessível na perspectiva arquitetônica (INEP, 2007, 2020). 
A acessibilidade arquitetônica deve ser considerada um elemento essencial à promoção da cidadania e da dignidade da pessoa humana, que são fundamentos da nossa república, que tem como objetivos: a construção de uma sociedade livre, justa e solidária, a redução das desigualdades sociais e a promoção do bem de todos, sem preconceitos e quaisquer outras formas de discriminação. A ideia da não discriminação pode ser lida no campo educacional pelo princípio que estabelece a necessidade de padrões mínimos de qualidade, definido pela LDB (BRASIL, 1996) como "a variedade e quantidade mínimas, por aluno, de insumos indispensáveis ao desenvolvimento do processo de ensinoaprendizagem".

Tal debate é complexo, especialmente quando se pensa o que seriam insumos indispensáveis para a garantia do direito à educação em padrões mínimos de qualidade para as pessoas com deficiência física. Isso amplia ainda mais a ideia de padrões mínimos, tendo em vista que esse mínimo precisa levar em consideração grupos com características bastante heterogêneas, bem como outras leis.

O objetivo deste trabalho é analisar as condições de oferta da infraestrutura escolar sob a perspectiva da acessibilidade arquitetônica às pessoas com deficiência física em algumas escolas públicas de ensino fundamental, anos iniciais da Rede Municipal de Ensino de Pinhais. Como o município de Pinhais/PR garante a acessibilidade arquitetônica para $\circ$ acesso e permanência dos alunos com deficiência física? Em quais condições de acessibilidade arquitetônica?

A oferta da educação escolar em condições de qualidade conforme as prerrogativas constitucionais é um dever do Estado. Schneider e Gouveia (2011) e Ximenes (2014) detalham as dimensões e os elementos dos deveres estatais, elencam vários itens, como a infraestrutura escolar, a acessibilidade arquitetônica e os materiais de ensino e aprendizagem, discutidos a seguir.

\section{A falta da acessibilidade arquitetônica e a desigualdade efetivada}

Com a obrigatoriedade de garantir uma educação básica obrigatória e gratuita dos 4 aos 17 anos de idade, esta oferta ocorre nas escolas públicas e privadas, urbanas e rurais, em instalações e serviços abertos ao público, logo, é necessário que todas sejam acessíveis.

Um dos documentos mais recentes, que foi sancionado no ano de 2015 , mas com vigência no ano de 2016, foi a lei brasileira de inclusão da pessoa com deficiência - LBI (BRASIL, 20I5), chamada também de Estatuto da pessoa com deficiência, que traz, em seu artigo $n^{\circ} 53$, a seguinte definição: "A acessibilidade é um direito que garante à pessoa com deficiência e com mobilidade reduzida viver de forma independente e exercer seus direitos de cidadania e de participação social [...]". E responsabiliza o poder público para que assegure, crie, desenvolva, implemente, incentive, acompanhe e avalie o sistema educacional inclusivo em todos os níveis e modalidades, o aprendizado ao longo de toda a vida, e a:

Olhar de professor, Ponta Grossa, v. 24, p. I-23, e-I8321.084, 202 I.

Disponível em <https://revistas2.uepg.br/index.php/olhardeprofessor> 
Acessibilidade para todos os estudantes, trabalhadores da educação e demais integrantes da comunidade escolar às edificações, aos ambientes $\mathbf{e}$ às atividades concernentes a todas as modalidades, etapas e níveis de ensino (BRASIL, 20I5, art. 28, grifo nosso).

Mas há garantia da acessibilidade nas escolas antes mesmo da LBI (BRASIL, 20I5), com a regulamentação da Lei ${ }^{\circ} 10048$ (BRASIL, 2000) e a Lei n 10098 (BRASIL, 2000), através do Decreto $n^{\circ} 5296$ (BRASIL, 2004), e antes mesmo da promulgação da Convenção Internacional sobre os Direitos das Pessoas com Deficiência (CDPCD) e seu Protocolo Facultativo pelo Decreto n 6949 (BRASIL, 2009).

Isso traz uma antiga questão, que é a existência de leis e sua falta de aplicação, justificada por diversos motivos pelos responsáveis, e neste caso, são analisados três, sendo o primeiro: escolas construídas com padrões construtivos anteriores as leis; o segundo pelos custos da adequação nas escolas e o terceiro justificado pela inexistência de alunos com deficiência física (CARDOZO, 202I).

As escolas construídas anteriormente às leis devem proporcionar condições de acesso e utilização, conforme declara o artigo n 24 do Decreto n 5296 (BRASIL, 2004):

Os estabelecimentos de ensino de qualquer nível, etapa ou modalidade, públicos ou privados, proporcionarão condições de acesso e utilização de todos os seus ambientes ou compartimentos para pessoas portadoras de deficiência ou com mobilidade reduzida, inclusive salas de aula, bibliotecas, auditórios, ginásios e instalações desportivas, laboratórios, áreas de lazer e sanitários.

É cristalino que não se exige a demolição de instalações ou prédios antigos, mas condições de acesso que anos depois a LBI (BRASIL, 20I5, art. 55), ao tratar da acessibilidade, exige; o atendimento aos princípios do desenho universal ${ }^{3}$ e às normas de acessibilidade NBR 9050 (ABNT, 2015). Ou seja, escolas construídas com padrões construtivos inacessíveis arquitetonicamente devem atender $\circ$ desenho universal em caso de reformas ou prédios novos e a adaptação razoável quando o desenho universal não é possível.

A adaptação das escolas existentes deve ser planejada pensando nos titulares desse direito, que são as pessoas com deficiência. Martel (201I, p. 105) explica que a adaptação é composta pelas "modificações, ajustes, amoldamentos e mesmo flexibilizações no ambiente material e normativo no qual é pleiteada, mediante emprego dos mais diversos mecanismos", sendo considerado: "a adaptação eficaz para o indivíduo ou grupo, incluindo-se na ideia de eficácia a prevenção e a eliminação da segregação, da humilhação e da estigmatização" (MARTEL, 20I I, p. 108).

3 Os princípios do desenho universal são: uso equitativo, uso flexível, uso simples e intuitivo, uso de fácil percepção, uso tolerante ao erro, uso com baixo esforço físico e uso com dimensões e espaços 9050 (ABNT, 20I5, ANEXO A). 
A adaptação razoável pela CDPCD (BRASIL, 2009, art. 2) e a LBI (BRASIL, 20I5) tem como significado:

[...] modificações e os ajustes necessários e adequados que não acarretem ônus desproporcional ou indevido, quando requeridos em cada caso, a fim de assegurar que as pessoas com deficiência possam gozar ou exercer, em igualdade de oportunidades com as demais pessoas, todos os direitos humanos e liberdades fundamentais (BRASIL, 2009, art. $2^{\circ}$ ).

Ou seja, as medidas necessárias para a acessibilidade devem ser realizadas com exceção de ônus desproporcional ou indevido. Seja a instalação de plataformas, elevadores, rampas, abertura de portas, identificações, enfim, tudo que for necessário para a efetivação do direito à educação e do direito à acessibilidade.

Mas os responsáveis, muitas vezes, tentam justificar a não adequação (ônus desproporcional ou indevido) pelo viés econômico, e nessa perspectiva a justiça brasileira já reconhece casos em que a acessibilidade arquitetônica em escolas foi exigida e recebeu ganho de causa para os requerentes. Os processos do Tribunal de Justiça do Estado do Paraná (TJ-PR): 0000954-10.20II.8.16.014I e 00I865665.20I4.8.16.0075, ambos de 2017, são exemplos da obrigatoriedade de adaptação e da não validade da justificativa econômica pelos responsáveis. Sendo o primeiro processo, em que o requerente teve ganho de causa devido ao poder executivo não garantir a eliminação de obstáculos arquitetônicos e de todas as formas de discriminação (dispositivo 244 da CF) (BRASIL, 1988). E o segundo processo, deferido pelo entendimento de que a garantia da acessibilidade arquitetônica é parte do direito a uma educação de qualidade (dispositivo 206 parágrafo VII da CF) (BRASIL, 1988).

Ao entrevistar diretoras de escolas acerca da acessibilidade arquitetônica em escolas públicas, foi identificado que:

\footnotetext{
A acessibilidade arquitetônica é percebida pelas gestoras como um direito, mas que somente se exige quando se apresenta alguém (comunidade escolar em geral) que necessite e se vincule à escola, para que as barreiras sejam eliminadas. Não se tem nos relatos a percepção pelas diretoras de que a acessibilidade arquitetônica é para todos e para garantir o acesso e permanência de modo seguro, autônomo e que a escola já deveria estar adequada ou em processo de adequação (CARDOZO, 202I, p. 102).
}

Esta evidência reforça a necessidade da ocupação dos espaços, mas principalmente que a adaptação das escolas necessita do reconhecimento do direito e da necessidade de exigi-lo. Não é considerada a acessibilidade arquitetônica como algo público, para todos, mas como uma necessidade individual, dificultando e postergando a adequação de ambientes escolares acessíveis. 
Assim, se percebe a exclusão de estudantes em espaços sem acessibilidade arquitetônica, um aprofundamento das desigualdades no que tange ao acesso, à permanência e ao processo pedagógico da escola em espaços parcialmente acessíveis.

\section{Mecanismos da desigualdade sob a ótica da acessibilidade arquitetônica}

Os estudos acerca da desigualdade educacional podem ser relacionados com um perfil quantitativo, e outros um perfil qualitativo. As questões qualitativas no estudo de Lucas (200I) são observadas em características dos estudantes e seu contexto social em determinada etapa do sistema educacional norte-americano. Por exemplo: o nível de educação dos pais, a ocupação, a renda bruta familiar, o gênero, a raça, as notas em exames de Matemática, Ciências, a frequência em exames preparatórios, entre outros. Parte do pressuposto de que, mesmo com a universalização do acesso, existe um grande impacto das questões sociais na trajetória escolar dos estudantes (LUCAS, 200I).

Ocorre uma busca dos familiares e seus filhos às escolas que têm melhor atendimento e infraestrutura para os alunos na perspectiva dos seus familiares, colocando mais uma vez a acessibilidade arquitetônica como um elemento de desigualdade, que ocorre devido à expansão educacional promovida pelo Estado brasileiro com as políticas de inclusão, que pode ser prevista na teoria de Lucas (200I) como dimensões qualitativas que contribuem com a manutenção das desigualdades educacionais.

Essa dinâmica explicada por Lucas (200I), nas conclusões de seu estudo:

[...] sugere que os efeitos do contexto social ocorrem de, pelo menos, duas maneiras: (I) determinam quem completa um nível de educação se a conclusão desse nível não é próximo de universal e (2) determinam o tipo de educação que as pessoas receberão em níveis próximos de universais ${ }^{4}$ (200I, p. I.68I, grifo nosso).

Quando os estudantes com deficiência estão em domicílios em que os responsáveis têm maior reconhecimento das suas necessidades e conhecimento dos direitos e garantias de responsabilidade do Estado, ou seja, da necessidade de ter a acessibilidade arquitetônica em escolas, em vias, um transporte acessivel, entre outros, possuem e buscam vantagens que os demais podem não ter. De outra quadra, estudantes que não têm esse suporte podem ficar em desvantagem quanto ao "tipo" de escola, seu acesso e permanência. Isso converge com a tese de Lucas (200I), em que as diferenças qualitativas são de extrema relevância e determinantes para o progresso escolar.

\footnotetext{
4 "This suggests that the effects of social background occur in at least two ways: (I) they determine who completes a level of education if completion of that level is not nearly universal, and (2) they determine the kind of education persons will receive within levels of education that are nearly universal" (LUCAS, 200I, p. I. 68I).
} 
É possível que todos aprendam quando têm condições de aprendizagem. Com o estímulo em quantidade e qualidade, condições adequadas de ensino e auxílio nas dificuldades de cada um, Crahay (2000) mostra, com os estudos de Bloom (1979), a ideologia da igualdade de conhecimento que tem como premissa a organização do ensino, em função do objetivo que todos devem atingir.

[...] a partir do momento em que a ciência mostra que as potencialidades de aprendizagem de um indivíduo não são fixadas a nascença, mas que, pelo contrário, são o fruto da história da sua vida, das suas experiências e da riqueza dos estímulos oferecidos nos seus meios, surgem novos horizontes e deveres. Torna-se legítimo reclamar para cada indivíduo, já não apenas o direito a igualdade de oportunidades ou à igualdade de tratamento, mas o direito à igualdade de conhecimentos de base (CRAHAY, 2000, p. 74-75).

Assim, é possível compreender a acessibilidade arquitetônica como elemento necessário para a exigência do direito à igualdade de conhecimentos de base, necessitando que as escolas e as políticas públicas tenham como princípio o controle das discriminações negativas e reforço das discriminações positivas. Cabe destacar que não se nega a importância da igualdade de oportunidades e de tratamento, ou seja, da necessidade de garantir os recursos e tratamento adequado, mas expõe a necessidade de ir além.

As formas de ideais de justiça na educação de Crahay (2000) permitem uma transposição no sentido de que a acessibilidade arquitetônica deve ser pensada como meio de permitir o acesso e a permanência, mas, também, como forma de possibilitar a aprendizagem. Sob essas lentes, é possível visualizar, numa perspectiva pedagógica, que a acessibilidade arquitetônica é um elemento que corrobora a redução da desigualdade de conhecimento e que pode também se apresentar como um elemento qualitativo da escola, pois sua existência traz igualdade de condições, promoção da autonomia, dignidade, e sua inexistência, exclusão para alguns.

Identificando que a acessibilidade arquitetônica é parâmetro qualitativo de uma escola e que interfere não somente no acesso e permanência à educação escolar, mas na progressão da vida acadêmica e, por consequência, na qualificação e até no acesso ao mercado de trabalho, os autores elencados, Crahay e Lucas, auxiliam na compreensão da acessibilidade arquitetônica como elemento de disputa, desigualdade e item qualitativo para a oferta de uma educação de qualidade, o que será analisado conforme os detalhamentos descritos a seguir.

\section{A mensuração da acessibilidade arquitetônica conforme o Censo escolar}

Através do Censo escolar, disponibilizado anualmente pelo Instituto Nacional de Estudos e Pesquisas Educacionais Anísio Teixeira - Inep, é possível ter um indicativo, de forma quantitativa e dicotômica, de alguns elementos acerca da acessibilidade arquitetônica. Há um parco levantamento de 
informações, ainda que, no último Censo Escolar (2019), tenha havido a ampliação das informações relativas a tal questão, que demonstram, em nível nacional, o desafio da garantia de uma escola acessível e a existência de escolas com oferta desigual, de modo geral.

Até o ano de 2019, era disponibilizado pelos dados do Censo escolar a existência ou não de: banheiro acessível (adequado ao uso de pessoas com deficiência ou mobilidade reduzida) e se as vias e dependências eram acessíveis. A partir do ano de 2019, é disponibilizada a observação da existência ou não de: corrimão e guarda corpos, elevador, pisos táteis, portas com vão-livre de no mínimo $80 \mathrm{~cm}$, rampas, sinalização sonora, sinalização tátil (piso/paredes), sinalização visual (piso/paredes) e banheiro acessível (adequado ao uso de pessoas com deficiência ou mobilidade reduzida).

Mesmo com o aumento do número de itens observados, é importante perceber que é rasa a informação acerca da condição da acessibilidade arquitetônica das escolas. Somente a existência dos itens propostos não permite saber sobre as condições dos elementos que podem impedir a utilização com autonomia e segurança. Há questões que tornam necessária a construção de um referencial mais refinado para comparar e indicar as características da acessibilidade arquitetônica nas escolas.

Nesse sentido, optou-se por levantar dados sobre acessibilidade arquitetônica, a partir de um roteiro de observação, além de se realizarem entrevistas com as diretoras das escolas, que permitiram um maior detalhamento e entendimento acerca da realidade local, inclusive do ponto de vista da gestão.

Toda essa complexidade de mensurar e qualificar os espaços, que não é sensível aos indicadores quantitativos existentes, conduz a instrumentos de coleta de dados que possam evidenciar, sob o viés de um pesquisador que realmente necessita da acessibilidade arquitetônica, a realidade das escolas. Desde o atravessar a rua da escola, percorrer o pátio, alcançar um livro na biblioteca, as ações possíveis da escola para se adaptar são exemplos de algumas das necessidades que podem ser captadas, observadas e sentidas com dois instrumentos de investigação propostos: o roteiro de observação e a entrevista com a direção escolar (KNECHTEL, 20I4).

\section{Proposta de um instrumento para coleta de dados primários}

A observação de forma passiva ou ativa exige cuidado com a subjetividade e influência que o observador tem sobre o que está sendo observado. O roteiro de observação é um conjunto de itens para verificação, que apresenta como opções quatro categorias: I. Se o item do roteiro faz parte da observação na escola, considerando a especificidade de cada escola; 2. O atendimento ou não do item observado conforme o espaço escolar; 3. A possibilidade de realizar a observação e chegar ao espaço, considerando-se que este pesquisador é cadeirante, pode haver situações em que, pela falta de acessibilidade arquitetônica, não seja possível verificar se o espaço está em conformidade ou não, de

Olhar de professor, Ponta Grossa, v. 24, p. I-23, e-I8321.084, 2021.

Disponível em <https://revistas2.uepg.br/index.php/olhardeprofessor> 
acordo com o roteiro de observação proposto; e 4. A existência ou não de determinado espaço/equipamento escolar.

Para uma melhor organização, o roteiro de observação nas escolas está dividido em cinco grupos de espaços, composto por 122 itens observáveis. São eles: I. O Entorno da escola, estacionamento e entradas (26 itens); II. Sala de aula, biblioteca ou sala de leitura, laboratório de informática ( 4 itens); III. Refeitório, Sanitários, recepção, bebedouro e auditório (43 itens); IV. Espaço para prática esportiva, parque e pátio ( 12 itens); V. Mobilidade entre corredores, entre pavimentos e sinalização (27 itens). No Quadro I, a seguir, está uma síntese ${ }^{5}$ do roteiro de observação:

Quadro I - Roteiro de observação simplificado

\section{O entorno da escola, estacionamento e entradas}

Existe guia (meio-fio) rebaixada ou faixa de pedestres elevada na quadra da escola?

O rebaixo de meio-fio está localizado em frente à faixa de pedestres ou nas esquinas onde houver travessia de pedestres?

Existe rebaixo de meio-fio associado à vaga para embarque e desembarque de Pessoa com Deficiência?

A rampa/guia tem inclinação inferior adequada?

A largura da rampa permite a passagem de uma cadeira de rodas e uma pessoa ao seu lado?

A rampa é sinalizada com piso tátil (para deficientes visuais) de alerta?

A quadra da escola tem faixa livre para pedestre com largura suficiente para um cadeirante e uma pessoa ao lado, livre de conflitos de circulação (pedestres $\mathrm{x}$ serviço $\mathrm{x}$ automóveis)?

É livre de obstáculos (elementos de mobiliário urbano como bancos, orelhões, postes, balizadores, canteiros, etc.) a faixa livre de circulação de pedestres da escola?

A entrada de veículos com guia rebaixada respeita a faixa livre exclusiva de pedestres?

Portão de acesso às garagens da escola, quando aberto, invade a faixa livre de circulação de pedestres?

Portão de acesso às garagens da escola tem sistema de sinalização visual e sonora?

No acesso principal à escola, existe o Símbolo Internacional do Acesso - SIA?

A entrada principal do prédio escolar é visualmente acessivel, ou seja, pode ser facilmente percebida?

Tem sinalização informativa e direcional da localização das entradas e saídas acessíveis?

Tem mapa acessível instalado imediatamente após a entrada principal com piso tátil associado, informando os principais pontos de distribuição no prédio ou locais de maior utilização?

Se existem dispositivos de segurança e para controle de acesso, do tipo catracas, cancelas, portas ou outros, pelo menos um deles é acessível, garantindo ao usuário acesso, manobra, circulação e aproximação para o manuseio do equipamento com autonomia e segurança?

A calçada/piso do entorno e das entradas é antiderrapante?

A calçada/piso do entorno e das entradas é contínua, regular, estável, sem ressaltos ou depressões?

Existe piso tátil de alerta onde necessário, próximo a desníveis, portas de acesso à escola, elementos de

5 Foi denominada síntese, pois está sem as questões referentes à mobilidade vertical (elevador e plataforma) e auditório, pois nenhuma escola possui estes equipamentos e espaço. 
mobiliário suspensos, escadas ou rampas, por exemplo?

Existe piso tátil direcional onde necessário (locais amplos e sem referência/balizamento) configurando uma rota acessível e conduzindo à entrada da escola?

O portão de acesso às garagens tem sistema de sinalização visual e sonora?

É possível acessar a escola do estacionamento com autonomia e segurança? (verificar rampas, elevadores, pisos planos, estáveis, faixas de pedestres e guias rebaixadas)

Existem $2 \%$ das vagas destinadas a veículos que transportem pessoa com deficiência com comprometimento de mobilidade, com, no mínimo, uma vaga?

Em vaga para Pessoa com Deficiência, existe placa de sinalização vertical com o Símbolo Internacional de Acesso e com identificação escrita?

As vagas reservadas têm sinalização horizontal (no piso) com o Símbolo Internacional do Acesso?

Cadeirantes e pessoas com mobilidade reduzida conseguem abrir totalmente a porta do veículo para embarque ou desembarque no estacionamento da escola? (considerar pessoas com muletas, andadores e cadeira de rodas)

\section{Sala de aula, biblioteca ou sala de leitura, laboratório de informática}

É possível um cadeirante chegar até a biblioteca escolar com autonomia e segurança?

Há possibilidade de um cadeirante transitar entre corredores da biblioteca?

É possível um cadeirante pegar sozinho um livro na prateleira (da mais baixa à mais alta)?

Se existirem mesas de estudo, uma cadeira de rodas consegue acessar e utilizar a mesa (altura e obstruções para as pernas)?

O piso da sala de aula e da entrada é contínuo, regular, estável, sem ressaltos ou depressões?

Cadeirantes, muletantes, pessoas com mobilidade reduzida, obesos conseguem circular na sala de aula?

Cadeirantes, muletantes, pessoas com mobilidade reduzida, obesos conseguem acessar e utilizar cadeiras e/ou mesas da sala de aula?

Cadeirantes, muletantes, pessoas com mobilidade reduzida, obesos conseguem acessar e utilizar a lousa da sala de aula?

Cadeirantes, muletantes, pessoas com mobilidade reduzida, obesos conseguem acessar e utilizar os equipamentos multimídias da sala de aula?

Cadeirantes, muletantes, pessoas com mobilidade reduzida, obesos conseguem acessar o laboratório?

O piso do laboratório e da entrada é contínuo, regular, estável, sem ressaltos ou depressões?

Cadeirantes, muletantes, pessoas com mobilidade reduzida, obesos conseguem circular no laboratório?

Cadeirantes, muletantes, pessoas com mobilidade reduzida, obesos conseguem acessar e utilizar o mobiliário do laboratório?

Cadeirantes, muletantes, pessoas com mobilidade reduzida, obesos conseguem acessar e utilizar os equipamentos/instrumentos do laboratório?

\section{Refeitório, Sanitários, recepção, bebedouro e auditório}

Nas superfícies de apoio para bandejas ou similares, as bandejas, os talheres, pratos, copos, temperos, alimentos e as bebidas podem ser alcançados pelos alunos e alunas (cadeirantes, andantes, muletantes, etc.)?

Os alimentos e as bebidas estão dispostos de forma a permitir o alcance visual?

Tem 5\% (com, no mínimo, uma do total) de mesas acessíveis para usuários de cadeira de rodas, sinalizadas com o SIA?

É garantida uma faixa de circulação entre as mesas e área de manobra para acesso (passagem que permita 
uma cadeira de rodas acessar e girar)?

Tratando-se de edificação nova - posterior a dez/2004, existe sanitário acessível, para cada sexo, em todos os pavimentos, com entrada independente dos sanitários coletivos?

Tratando-se de edificação antiga - anterior a dez/2004, ela dispõe de, pelo menos, um sanitário acessível, por pavimento, com entrada independente dos sanitários coletivos?

É possível acessar o sanitário com autonomia e segurança (cadeirantes e pessoas com mobilidade reduzida)?

Os sanitários acessíveis estão próximos ou integrados às demais instalações sanitárias?

Os sanitários acessíveis têm dispositivo de sinalização de emergência (alarme sonoro e visual) próximo à bacia, acionado através de pressão ou alavanca com cor contrastante?

A entrada do sanitário tem desnível?

A porta do sanitário permite a entrada de uma pessoa que utiliza cadeira de rodas?

O sentido de abertura da porta é para fora?

No caso de boxe acessível, a porta do sanitário no qual ele está inserido abre para fora ou há espaço ao lado da porta para facilitar sua abertura?

A maçaneta é do tipo alavanca?

A porta tem puxador horizontal?

Existe sinalização visual e sinalização tátil em relevo e braille ou sonora?

É possível circular no ambiente sanitário com autonomia e segurança?

É possível colocar uma cadeira de rodas ao lado do assento sanitário?

Existem barras de apoio próximas ao vaso sanitário?

O acionamento da válvula de descarga atende à altura máxima de $\mathrm{I} \mathrm{m}$ e é de fácil acionamento?

O lavatório permite aproximação para Pessoa com Deficiência (pernas abaixo do lavatório)?

As torneiras são acionadas por alavanca, sensor eletrônico ou dispositivo equivalente?

Os acessórios (cabide, saboneteira, toalheiro, porta-objeto) são de fácil alcance?

Os bebedouros estão instalados com, no mínimo, duas alturas diferentes de bica em relação ao piso acabado?

Há possibilidade de aproximação frontal sob o bebedouro?

Os outros modelos de bebedouro (garrafão, filtro, etc.), assim como o manuseio dos copos, permitem a aproximação lateral e utilização de uma pessoa com cadeira de rodas?

O balcão de atendimento da recepção está facilmente identificado e localizado em caminho acessível (cadeirantes, muletantes, pessoas com mobilidade reduzida, obesos chegam até o balcão/recepção)?

O balcão de atendimento da recepção tem profundidade de modo que a pessoa em cadeira de rodas tenha a possibilidade de avançar sob o balcão?

O balcão de atendimento da recepção tem o Símbolo Internacional de Acesso próximo à parte rebaixada?

\section{Espaço para prática esportiva, parque e pátio}

Cadeirantes, muletantes, pessoas com mobilidade reduzida, obesos conseguem acessar o espaço para a prática esportiva?

É possível acessar o espaço com autonomia e segurança (cadeirantes e pessoas com mobilidade reduzida)?

Os sanitários acessíveis estão próximos ou integrados às demais instalações sanitárias?

Cadeirantes, muletantes, pessoas com mobilidade reduzida, obesos conseguem acessar a arquibancada do espaço para a prática esportiva? 
Existe piso tátil direcional e de alerta?

O piso é antiderrapante, regular, estável e não trepidante?

Existe piso tátil de alerta onde necessário, próximo a desníveis, elevadores, elementos de mobiliário suspensos, escadas ou rampas, por exemplo?

Há iluminação artificial?

Há iluminação natural?

No pátio ou espaço de circulação, há livre passagem sem interrupções por mobiliário, vaso de planta, elementos suspensos, que ofereçam riscos, etc.?

É possível um cadeirante chegar até o parque, com autonomia e segurança?

Existe brinquedo adaptado para a utilização crianças com deficiência e/ou mobilidade reduzida?

\section{Mobilidade entre corredores, entre pavimentos e sinalização}

Existem placas de sinalização informando sobre os sanitários, acessos verticais e horizontais e números de pavimentos?

A sinalização está disposta em locais acessíveis para pessoa em cadeira de rodas, com deficiência visual, entre outros usuários, de tal forma que possa ser compreendida por todos?

Há placas indicando os atendimentos preferenciais disponíveis?

Existe piso tátil direcional e de alerta?

O piso é antiderrapante, regular, estável e não trepidante?

Possui piso tátil de alerta onde necessário, próximo a desníveis, elevadores, elementos de mobiliário suspensos, escadas ou rampas, por exemplo?

Há iluminação artificial no corredor?

No espaço de circulação, há livre passagem sem interrupções por mobiliário, vaso de planta, elementos suspensos, que ofereçam riscos, etc.?

Há outros andares (pavimentos) no prédio escolar ou anexos?

Existem escadas?

Existem rampas?

Existe elevador ou plataforma elevatória?

A rampa/guia tem inclinação adequada?

A largura da rampa permite a passagem de uma cadeira de rodas e uma pessoa ao seu lado?

Existe faixa de piso tátil de alerta no início e término da rampa?

Os corrimãos das rampas são construídos em materiais rígidos e resistente, firmemente fixados às paredes, e oferecem condições de segurança na utilização?

A calçada/piso das rampas é antiderrapante?

A calçada/piso das rampas é contínua, regular, estável, sem ressaltos ou depressões?

O corrimão prolonga-se antes do início e após o término da rampa?

O piso da cabine do elevador tem superfície rígida e antiderrapante?

Fonte: Elaborado pelo autor, 202I.

Outra fonte de dados primária proposta para a coleta de dados é a entrevista, que constitui mais uma fonte de evidências para descobertas sobre a questão enunciada. Com o roteiro de 
observação, será evidenciado o espaço escolar, seu aspecto físico, e com a realização da entrevista semiestruturada, serão evidenciados aspectos sociais, especificamente o olhar da gestão local da escola através da direção escolar.

Explica Mendes (2018, p. 26) que "a atualização do conhecimento sobre acessibilidade é necessária, tendo em vista a existência de diversas legislações e normas sobre o assunto e ainda o fato de as mesmas sofrerem constantes modificações". Assim, a percepção da direção escolar é uma fonte importante de informações, por se tratar do primeiro gestor com quem os pais ou responsáveis fazem contato para matricular seus filhos e são dependentes das decisões desses gestores à permissão de ingresso na escola, sendo também uma das primeiras pessoas de quem se possa exigir, de forma administrativa, a adequação do espaço físico.

As entrevistas foram realizadas de forma presencial, com preenchimento do termo de consentimento livre esclarecido e respeitando os protocolos de saúde do município. Somente em uma escola não foi possível entrevistar a diretora de forma presencial, por divergência de agendas e horários; por isso, foi enviado o roteiro de entrevista e respondido por interação, via aplicativo multiplataforma de mensagens instantâneas e chamadas de voz. A seguir, o Quadro 2 apresenta o roteiro semiestruturado para a realização das entrevistas.

Quadro 2 - Roteiro da entrevista semiestruturada

Qual sua formação acadêmica?

Há quanto tempo trabalha na RME de Pinhais? Antes de atuar como diretor, atuava como professor/professora (em que etapa/ano)?

Há quanto tempo trabalha nessa escola? Há quanto tempo é diretor(a) dessa escola?

Quais os maiores desafios da direção escolar?

E, em relação à questão do atendimento às pessoas com deficiência, transtornos globais do desenvolvimento, quais são os desafios?

No que se refere à acessibilidade, como você entende esse conceito e sua importância para a escola?

Você acredita que a escola possui uma boa acessibilidade arquitetônica?

Foram feitas melhorias no que se refere a essa questão nos últimos anos?

Há recursos para investimento no que se refere à melhoria da acessibilidade arquitetônica? Quais são as fontes desses recursos?

A Secretaria de Educação tem demonstrado preocupação com a questão da acessibilidade arquitetônica e, se sim, como?

Quais as dificuldades que você percebe em termo de acessibilidade?

Existem alunos cadeirantes ou cegos na escola? Quais os tipos de deficiência que existem na escola?

Já houve reclamações ou solicitações sobre a acessibilidade? Quais?

Qual a maior dificuldade da inclusão?

E quanto à adaptação do espaço físico? 
Já recebeu algum pai, funcionário ou alguma pessoa da comunidade que necessitava de acessibilidade arquitetônica e não havia?

Em caso positivo, quais encaminhamentos foram tomados pela escola, pela secretaria?

Como você avalia a política de inclusão no Brasil? E a política municipal para alunos com necessidades educacionais especiais?

Fonte: Elaborado pelo autor, 2021.

Uma vez elucidadas as formas de coleta dos dados primários, os critérios para a escolha das amostras para a realização da evidência empírica são tratados a seguir.

\section{As escolas analisadas no município de Pinhais}

O município de Pinhais está localizado na região metropolitana de Curitiba, faz fronteira com a capital do estado do Paraná, junto com 28 municípios que compõem a região. Oficialmente, virou município no ano de 1992, pela Lei Estadual ${ }^{\circ}$ 9.906, de 18 de março de 1992, e tem a menor área se comparado aos demais 398 municípios do estado. É um município que tem sua formação política recente e está entre os 15 com maior arrecadação do estado do Paraná, destacando-se por ser uma região com muitas indústrias, com destaque para a indústria de metal, mecânica e plásticos. Conforme o último Censo disponibilizado pelo Instituto Brasileiro de Geografia e Estatística (IBGE), realizado no ano de 2010, Pinhais configura-se como a $14^{\text {a }}$ maior cidade paranaense em população, com mais de II 7 mil habitantes. Desses, 8.424 pessoas possuem deficiência.

A escolha pelo município de Pinhais/PR ocorreu pela autorização de realização da pesquisa durante a pandemia de Covid-19, proximidade geográfica e existência de um sistema educacional próprio.

Por se tratar de um estudo de caso, é fundamental a definição e explicação dos critérios que conduziram a escolha das escolas, sendo um deles o maior número de matrículas. $\mathrm{O}$ município de Pinhais/PR tem $58,21 \%$ das matrículas no ensino fundamental - anos iniciais (EF-Al), logo, a escolha das escolas de ensino fundamental se dá, primeiro, por representar o maior percentual de estudantes, além disso, entende-se que a acessibilidade arquitetônica em instituições que atendem creche e pré-escola exigem um outro olhar.

A fim de selecionar escolas para aplicar o roteiro de observação e entrevistar as diretoras, foi criada uma base de dados contendo as informações quanto aos alunos matriculados e à acessibilidade arquitetônica, sendo as variáveis quantitativas discretas: número de matrículas nas escolas dos alunos, número de alunos com deficiência física, número de alunos com NEE e $\circ$ ano da autorização do funcionamento da escola. E as variáveis qualitativas nominais, como: nome da escola, código, endereço, existência de corrimão e guarda-corpos, existência de elevador, existência de pisos táteis, existência de portas com vão-livre de no mínimo $80 \mathrm{~cm}$, existência de rampas, existência de sinalização sonora, 
existência de sinalização tátil (piso/paredes), existência de nenhum dos recursos de acessibilidade listados, existência de sinalização visual (piso/paredes), e existência de banheiro acessível adequado ao uso de pessoas com deficiência ou mobilidade reduzida.

A variável do ano de criação da escola é significativa, pois permite identificar o perfil de construção da escola considerando a educação do período de acordo com a política às pessoas com deficiência. Das 21 escolas selecionadas, em média, sua data de criação no município é da década de 90.

A partir do banco de dados criado, foram selecionadas as escolas a serem observadas. A população se refere às 21 escolas regulares de ensino comum que ofertam o EF-Al, sendo 4 selecionadas pelos critérios de maior representatividade, sempre com seu oposto (maior e menor quantidade ou mais recente e menos recente), com o intuito de ter amostras comparativas entre si.

Os critérios definidos foram: i. Número de matrículas; ii. Número de matrículas de alunos com deficiência física; e iii. Ano de início do funcionamento da escola.

Após a aplicação dos critérios e as condições mencionadas, foram selecionadas as escolas: Antonio Andrade, Poty Lazzarotto, Chafic Smaka e Antonio Alceu Zielonka.

Quadro 3 - Escolas (amostras) selecionadas para verificação em campo

\begin{tabular}{|c|c|c|}
\hline Critério & Escola & Resultado \\
\hline \multirow{2}{*}{ Número de matrículas } & Antonio Andrade (AA) & 989 (maior) \\
\cline { 2 - 3 } & Poty Lazzarotto (PL) & 104 (menor) \\
\hline \multirow{2}{*}{$\begin{array}{c}\text { Número de alunos com } \\
\text { deficiência física }\end{array}$} & Chafic Smaka(CS) & 7 (maior) \\
\cline { 2 - 3 } Ano de funcionamento & Antonio Alceu Zielonka (AZ) & 0 (menor) \\
\cline { 2 - 3 } & Poty Lazzarotto(PL) & 2010 (mais recente) \\
\hline \multirow{2}{*}{ Chafic Smaka (CS) } & 1977 (mais antiga) \\
\hline
\end{tabular}

Fonte: Elaborado pelo autor com referência no INEP, 2019.

A seguir, o resultado da observação nas escolas, segundo os instrumentos de coleta propostos.

\section{Resultados}

Os dias das visitas nas escolas Alceu Zielonka (AZ), Poty Lazzarotto (PL) e Antonio Andrade (AA) estavam nublados e com chuvas de intensidade leve a moderada. Essas informações são relevantes, pois se somam às barreiras arquitetônicas. No caso de utilizadores de próteses e/ou órteses (cadeira de rodas, muleta, prótese de membros, etc.), é experimentar, como no caso deste pesquisador, usuário de cadeira de rodas, o aro que fica liso e impede a propulsão da cadeira, os tecidos e espumas que molham e não tem a possibilidade de troca ou fácil secagem, não há como "correr" ou 
simplesmente "tocar" ou "rodar" a cadeira mais rápido para chegar na escola. Ou se espera a chuva passar, ou é necessário o auxílio de uma pessoa, o que pode ser perigoso, pois é possível uma queda pela imperícia junto à falta ou má conservação de acessibilidade arquitetônica nas vias de acesso à escola.

Para a análise das quatro escolas em relação aos itens propostos e observados, chegou-se aos resultados, conforme a Tabela I, a seguir, que informa os totais mencionados e a observação dos itens de cada escola, conforme proposto.

Tabela I - Resultado da observação da acessibilidade arquitetônica nas escolas em pinhais, 2020*

\begin{tabular}{|c|c|c|c|c|}
\hline \multirow{2}{*}{ Escola } & \multicolumn{3}{|c|}{ Itens } \\
\cline { 2 - 5 } & Observados & Atendidos & $\begin{array}{c}\text { Não foi possível } \\
\text { verificar }\end{array}$ & $\begin{array}{c}\text { Não possui } \\
\text { espaço/equipamento }\end{array}$ \\
\hline $\begin{array}{c}\text { Antonio Alceu Zielonka } \\
\text { (AZ) }\end{array}$ & 94 & 36 & 0 & 14 \\
Poty Lazzarotto (PL) & 75 & 2 & 5 & 28 \\
Antonio Andrade (AA) & 99 & 55 & 0 & 9 \\
Chafic Smaka (CS) & 95 & 35 & 0 & 13 \\
TOTAL & $\mathbf{3 6 3}$ & $\mathbf{1 5 8}$ & $\mathbf{5}$ & $\mathbf{6 4}$ \\
\hline
\end{tabular}

Fonte: $\mathrm{O}$ autor, 2021.

*desconsidera auditórios

O percentual de atendimento é calculado pela quantidade de itens atendidos em relação aos itens observados por escola e a distância percentual para que a escola alcance a escola com maior atendimento aos itens de acessibilidade arquitetônica, neste caso, a escola AA com 55,6\% de atendimento dos itens.

Os atendimentos percentuais das escolas são: AA (55,6\%), PL (42,7\%), AZ (38,3) e CS (36,8\%). A escola PL não tem acesso ao pavimento superior, o que deve ser considerado grave, pelo "tamanho" da barreira, que não permite acessar as salas de aula. Nenhuma escola tem uma rota acessível que permita ocupar os espaços das escolas conforme o conceito do termo inscrito em lei; este retrato impede que pessoas com deficiência tenham assegurado o direito à educação.

Há convergência destas situações com os postulados de Crahay (2000) e Lucas (200I), ao pensar que a escola está impedindo a igualdade de conhecimento de base, reproduzindo desigualdades e aprofundando desvantagens. Também, impedindo, de certa forma, o desenvolvimento da autonomia e da cidadania dos estudantes.

Para que as escolas PL, AZ e CS se aproximem da escola AA, é necessário atender a 23,3\%, 3 I, I\% e 33,7\% dos itens observados em cada escola, respectivamente. Essa desigualdade entre escolas, 
produzida pela falta da acessibilidade arquitetônica, é relevante e deve ser analisada de forma sistêmica, para seu enfrentamento, pois fica evidente que pode a acessibilidade arquitetônica ser um dos muitos mecanismos de seleção escolar.

As gestoras das escolas têm um unânime entendimento acerca da importância da acessibilidade arquitetônica. Todas afirmam que a acessibilidade arquitetônica é fundamental, mas desconhecem os requisitos inscritos em lei, normativas técnicas ou não a exigem pelo fato de não perceberem a necessidade em sua gestão, que pode ser traduzida pela não existência de professor, aluno, pais, terceiros, que exijam um espaço acessível. Nas palavras das diretoras, a acessibilidade arquitetônica é:

Fundamental. Deveriam ter todas as condições para atender todas as especificidades, sejam elas motoras, intelectuais, todas elas. Tanto em questão de recursos, como aparatos tecnológicos e a questão da infraestrutura mesmo (CARDOZO, 2021, p.103)

Eu vejo que o acesso à permanência na escola é direito de todos. Então a gente tem que buscar um caminho para que possamos atender a todos (CARDOZO, 202I, p.103)

Importante ressaltar os direitos que todo cidadão com uma condição, de acessibilidade deverá ter, ser reconhecida e compreendida que existe uma potencialidade, que ela é capaz de desenvolver e exercer funções com bastante eficiência. Cabe ao Estado garantir os direitos e ofertar condições favoráveis a todos. $\mathrm{Na}$ escola essa diversidade é de extrema importância, pois é um constante aprendizado e trocas ricas de experiências entre pessoas, despertando assim, o espírito de convivência, respeito e reconhecimento que todos somos iguais e temos nossas diferenças em todos os aspectos e potencialidades (CARDOZO, 202 I, p. I03)

Eu acho que precisa ter. Hoje a gente não tem como não ter acessibilidade, porque a escola tá aberta para todos, seja como aluno ou seja como um pai que vem até a escola. Porque nós temos uma mãe que é cadeirante, até quando ela falou que...que eu não sabia que você, que você era portador né, tinha a questão do uso da cadeira, então ela falou é um cadeirante que falar com você né, daí eu até achei que era a mãe do Luiz, porque a mãe do Luiz ela é, né, daí eu falei... ah! Já sei quem é, é o Raphael. Então é importante por isso, porque você tem os alunos, você tem os pais dos alunos, pessoas que nascem e pessoas que vem a passar a usar, então precisa ter. Hoje em dia não tem como você não abrir essa acessibilidade (CARDOZO, 2021, p. 104).

A acessibilidade arquitetônica é percebida pelas gestoras como um direito, mas que somente é exigido e reclamado quando se apresenta alguém (comunidade escolar em geral) que necessite e se vincule à escola, para que as barreiras sejam eliminadas. Não se tem, nos relatos, a percepção pelas diretoras de que a acessibilidade arquitetônica serve para garantir o acesso e a permanência, de modo seguro, autônomo, e que a escola já deveria estar adequada ou em processo de adequação.

A gente é muito limitado, não temos nesse prédio hoje condição para atender crianças com acessibilidade, é claro que a gente pode reestruturar, reorganizar o espaço, mas com algumas limitações. Se for necessário a gente consegue atender, é como eu te disse, remanejando turma daqui para sala, reorganizando os espaços. É

Olhar de professor, Ponta Grossa, v. 24, p. I-23, e-I8321.084, 2021.

Disponível em <https://revistas2.uepg.br/index.php/olhardeprofessor> 
claro que algumas coisas precisam ser melhoradas, como você viu a dificuldade que você já teve para subir no degrau do meio-fio ali, que a gente não tem, e quando eu me dei conta, falei, nossa! A gente não tem acesso ali, então é uma coisa da gente buscar isso para poder atender quando for preciso (CARDOZO, 202 I, p. I02).

Esses relatos chamam a atenção, pois demonstram a importância do contexto social e corroboram a teoria de Lucas (200I). Ressalta-se, também, que: "O acesso ao ensino obrigatório e gratuito é direito público subjetivo" (BRASIL, 1988 , art. 208, $\S 1^{\circ}$ ) e devem ser exigidos pelo pelos responsáveis públicos governamentais, sociedade e família, uma vez que se trata de estudantes que ainda estão se reconhecendo como sujeito de direitos.

Entende-se que a desigualdade da acessibilidade arquitetônica compõe o conjunto díspar e complexo de causas da desigualdade escolar, conforme apresentam Oliveira e Araújo (2005), confirmando que a igualdade de oportunidades se torna cada vez mais distante entre as escolas e da legislação vigente.

É notório que as evidências identificadas aqui corroboram com algumas literaturas apresentadas e avançam de forma meticulosa na identificação da desigualdade da acessibilidade arquitetônica nas escolas. Isso permite identificar e avaliar a implementação das políticas educacionais voltadas à inclusão e à acessibilidade arquitetônica, e, com isso, a promoção da garantia do direito à educação para todos.

\section{Considerações finais}

O resultado deste trabalho mostra que há muito para avançar nas escolas municipais de Pinhais em relação à acessibilidade arquitetônica e que ela somente ocorrerá com a compreensão de que o direito à educação engloba o direito à acessibilidade. A existência de políticas educacionais sob a perspectiva inclusiva auxilia na implementação da acessibilidade arquitetônica. Ficou evidente o descumprimento de normas e o mecanismo de mudança desses espaços públicos coletivos, que somente ocorrerão com a ocupação desses espaços por pessoas com deficiência, seja por funcionários, alunos ou pais, toda a comunidade escolar.

Somente os dados quantitativos não permitem o diagnóstico da realidade das escolas sobre o tema, tornando fundamental a avaliação qualitativa, uma vez que os parâmetros inscritos em normas técnicas não são conhecidos ou executados pela gestão das escolas e seus interlocutores. Precisam ser avaliados por equipes técnicas, que nem sempre compõem os conselhos, que são os responsáveis pela autorização de funcionamento das escolas.

Foi possível responder à questão-problema deste trabalho com as técnicas de pesquisa propostas para identificar de que forma está sendo garantida a acessibilidade arquitetônica para o 
acesso e permanência dos alunos com deficiência física em escolas que ofertam anos iniciais do ensino fundamental no município de Pinhais.

A acessibilidade arquitetônica é uma das características da escola que promove a igualdade de oportunidade, de tratamento e de conhecimento, auxiliando no desenvolvimento dos estudantes e tornando o espaço escolar um conjunto de ambientes democráticos. De outra quadra, sua falta, evidenciada neste trabalho, gera uma desigualdade que exclui em seu grau máximo, mas que pode oprimir e impedir o desenvolvimento da aprendizagem e da autonomia. É o caso do acesso a uma biblioteca ou a uma sala, que somente com o auxílio de outras pessoas é possível pela existência de um desnível (degrau na porta de entrada).

O referencial quantitativo deve ser utilizado com cuidado, pois um item pode impedir o acesso à escola de forma autônoma e segura. Não existe uma escola 100\% acessível, mas uma escola com maior garantia de elementos da acessibilidade arquitetônica e maior promotora de autonomia e segurança. É relevante observar que o roteiro elenca elementos presentes em normas nacionais, que deveriam ser observados para garantir a efetivação do direito, mas também da liberdade de locomoção e o desenvolvimento da autonomia dos estudantes com deficiência.

A desigualdade das escolas que ofertam a mesma etapa no mesmo município, através do mecanismo da Desigualdade Efetivamente Mantida de Lucas (200I), foi evidenciada, e ao se identificar, de forma quantitativa, o tamanho da desigualdade no conjunto de itens observados no aspecto da acessibilidade arquitetônica, ficou cristalino que a ideologia da igualdade de oportunidade e de tratamento explicada por Crahay (2010) se faz presente nas conduções e tomadas de decisões para mudança pelas gestoras.

Isto é, não se percebe a acessibilidade arquitetônica como algo necessário para a escola, mas, sim, como reforma necessária apenas se houver um indivíduo que dela necessite. Isso explica as distâncias percentuais entre as escolas, pois as escolas com maior percentual de atendimento aos itens observados são as que apresentam, no caso da escola AA, e que já tiveram, no caso da escola PL, estudantes com deficiência física.

Não foi identificada relação com o ano de funcionamento ou número de estudantes, mas a presença de alunos que precisam da acessibilidade arquitetônica nas escolas, relatado em entrevista pelas diretoras.

Ainda com adaptações realizadas, a acessibilidade arquitetônica foi identificada como mecanismo de seleção para o acesso e permanência nas escolas para um público específico, mostrando a falta dos conceitos do Desenho Universal, da própria legislação e das normas, que indicam parâmetros para construir e adaptar ambientes e mobiliários, tornando-os acessíveis. 
Fica evidente um ciclo vicioso, em que o aluno que precisa da acessibilidade arquitetônica acessa uma escola que não está adaptada e, com isso, renuncia o desenvolvimento da autonomia, da segurança e da oportunidade de conhecimento. Este e seus familiares, com esperança de que as mudanças aconteçam, solicitam para a gestão. A partir da solicitação, devem ser apresentados projeto, recursos e o planejamento para a execução e aprovação, afinal, são obras de infraestrutura e requerem tempo.

Tal morosidade faz com que se naturalize a dependência, a segregação e o tratamento diferenciado para acessar, utilizar e interagir nos espaços da escola. Conforme se dão os prazos, ocorre a evasão para uma escola considerada "mais acessível" ou pela progressão das etapas, deixando de ser priorizada a adequação da escola, o que é justificado pela não existência de pessoas que "precisam", mudança de gestão, recursos técnicos, financeiros, impossibilidade de reformas com a escola em funcionamento e muitas outras. Logo, retorna-se à situação inicial e se revela a inércia na adaptação das escolas e na garantia do direito à educação, reforçando-se a ampliação das políticas educacionais com vistas à acessibilidade.

É necessário o aprimoramento do roteiro de observação para aprofundar o diagnóstico local e as análises, como identificar o número de acessos, de rampas, escadas, os equipamentos utilizados em aulas, para prática esportiva, por exemplo. Também, para melhor diagnosticar a oferta do município, realizar o roteiro de observação e entrevistas junto às 21 escolas que ofertam o EF-Al. Além disso, análises da política do município para a educação especial e as ações do conselho municipal de educação podem complementar as observações aqui apresentadas.

\section{Referências}

ASSOCIAÇÃO BRASILEIRA DE NORMAS TÉCNICAS (ABNT). NBR 9050: Acessibilidade a edificações, mobiliário, espaços e equipamentos urbanos. Rio de Janeiro, 2015.

BRASIL. Constituição (1988) Constituição: República Federativa do Brasil. Brasília, DF: Senado Federal, 1988. Disponível em: http://www.planalto.gov.br/ccivil_03/Constituicao/Constituicao.htm. Acesso em: I 4 nov. 2020.

BRASIL. Lei $n^{\circ}$. 10.048 de 8 de novembro de 2000. Dá prioridade de atendimento às pessoas que especifica, e dá outras providências. Diário Oficial da União, Brasília, DF, 2000. Disponível em: http://www.planalto.gov.br/ccivil_03/Leis/LI 0048.htm. Acesso em: I I fev. 202 I.

BRASIL. Lei $\mathrm{n}^{\circ}$. 10.098 de 19 de dezembro de 2000. Estabelece normas gerais e critérios básicos para a promoção da acessibilidade das pessoas portadoras de deficiência ou com mobilidade reduzida, e dá outras providências. Diário Oficial da União, Brasília, DF, 2000. Disponível em: http://www.planalto.gov.br/ccivil_03/Leis/LI 0098.htm. Acesso em: II fev. 202I. 
BRASIL. Lei no 9.394 de 20 de dezembro de 1996. Estabelece as diretrizes e bases da educação nacional. Diário Oficial da União, Brasília, DF, 1996. Disponível em:

http://portal.mec.gov.br/seed/arquivos/pdf/tvescola/leis/lein9394.pdf. Acesso em: 8 mar. 202I.

\section{BRASIL. Secretaria de Educação Especial. Política Nacional de Educação Especial na}

Perspectiva da Educação Inclusiva. Brasília, DF, jan. 2008. [Documento elaborado pelo Grupo de Trabalho nomeado pela portaria n. 555/2007, prorrogada pela portaria n. 948/2007, entregue ao ministro da Educação em 7 de janeiro de 2008]. Disponível em:

http://portal.mec.gov.br/arquivos/pdf/politicaeducespecial.pdf. Acesso em: 22 out. 2020.

BRASIL. Lei $n^{\circ} 13.146$ de 6 de julho de 2015. Institui a Lei Brasileira de Inclusão da Pessoa com Deficiência (Estatuto da Pessoa com Deficiência). Diário Oficial da União, Brasília, DF, 2015. Disponível em:http://www.planalto.gov.br/CCIVIL_03/_Ato20I5-20I8/20I5/Lei/LI3 I46.htm. Acesso em: II dez. 2020.

BRASIL. Decreto ${ }^{\circ}$ 3.298, de 20 de dezembro de 1999: Regulamenta a Lei n. 7.853, de 24 de outubro de 1989 e dá outras providências. Diário Oficial da União, Brasília, DF, 1999. Disponível em: http://www.planalto.gov.br/ccivil_03/decreto/D3298.htm. Acesso em: 24 maio 2021.

BRASIL. Lei $n^{\circ}$ 13.005, de 25 de junho de 20I4. Aprova o Plano Nacional de Educação e dá outras providências. Diário Oficial da União, Brasília, DF, 2014. Disponível em:

http://www.planalto.gov.br/ccivil_03/_Ato20II-20I4/20I4/Lei/LI3005.htm. Acesso em: I4 jan. 20 I8.

BRASIL. Conselho Nacional de Educação. Câmara de Educação Básica. Resolução n. 08, de 05 de maio de 2010 . Estabelece normas para aplicação do inciso IX do artigo $4^{\circ}$ da Lei $n^{\circ} 9.394 / 96$ (LDB), que trata dos padrões mínimos de qualidade de ensino para a Educação Básica pública. Brasília, DF, 2010. Disponível em:

http://portal.mec.gov.br/index.php?option=com_docman\&view=download\&alias=5063-parecercneseb8-20 I0\&Itemid=30192. Acesso em: 23 jan. 2018.

BRASIL. Decreto $n^{\circ}$ 6.949, de 25 de agosto de 2009. Promulga a Convenção Internacional sobre os Direitos das Pessoas com Deficiência e seu Protocolo Facultativo, assinados em Nova York, em 30 de março de 2007. Diário Oficial da União, Brasília, DF, 2009. Disponível em:

https://www.planalto.gov.br/ccivil_03/_ato2007-2010/2009/decreto/d6949.htm, Acesso em: 14 mar 2018.

BRASIL. Decreto n 5.296, de 2 de dezembro de 2004. Regulamenta as Leis nos 10.048, de 8 de novembro de 2000, que dá prioridade de atendimento às pessoas que especifica, e 10.098, de 19 de dezembro de 2000, que estabelece normas gerais e critérios básicos para a promoção da acessibilidade das pessoas portadoras de deficiência ou com mobilidade reduzida, e dá outras providências. Diário Oficial da União, Brasília, DF, 2004. Disponível em: http://www.planalto.gov.br/ccivil_03/_Ato2004-2006/2004/Decreto/D5296.htm, Acesso em: 14 mar 2018.

BRASIL. Ministério da Educação. Conselho Nacional da Educação. Parecer CNE/CEB n. ${ }^{\circ}$ 4/2009. Institui Diretrizes Operacionais para o Atendimento Educacional Especializado na Educação Básica, modalidade Educação Especial. Brasília: MEC, 2009.

CARDOZO, R. D. Acessibilidade arquitetônica, deficiência física e o direito à educação : um olhar em escolas municipais de Pinhais. Dissertação (Mestrado em Educação) - Universidade Federal do Paraná - UFPR, Curitiba, 202I. I80p. 
CRAHAY, M. Poderá a escola ser justa e eficaz? Da igualdade de oportunidades à igualdade dos conhecimentos. Lisboa: Instituto Piaget, 2000.

INSTITUTO NACIONAL DE ESTUDOS E PESQUISAS EDUCACIONAIS ANÍSIO TEIXEIRA (INEP). Censo Escolar 2007. Brasília: Inep, 2007. Disponível em: http://inep.gov.br/web/guest/microdados. Acesso em: 30 jun. 2021.

INSTITUTO NACIONAL DE ESTUDOS E PESQUISAS EDUCACIONAIS ANÍSIO TEIXEIRA (INEP). Censo Escolar 2019. Brasília: Inep, 2019. Disponível em: http://inep.gov.br/web/guest/microdados. Acesso em: 30 jan. 2021.

INSTITUTO NACIONAL DE ESTUDOS E PESQUISAS EDUCACIONAIS ANÍSIO TEIXEIRA (INEP). Censo Escolar 2020. Brasília: Inep, 2020. Disponível em: http://inep.gov.br/web/guest/microdados. Acesso em: 30 jan. 2021 .

KNECHTEL, M. do R. Metodologia da pesquisa em educação: uma abordagem teórico-prática dialogada. Curitiba: Intersaberes, 2014.

LUCAS, S. R. jun. 20II •. American Journal of Sociology, v. I06, n. 6, p. 1642-1690, 200 I. Disponivel em: https://www.jstor.org/stable/I0.1086/32I300?seq=I. Acesso em: 7 mar. 202I.

MARTEL, L. de C. V. Adaptação razoável: o novo conceito sob as lentes de uma gramática constitucional inclusiva. Revista Internacional de Direitos Humanos, v. 8, n. I4, p. 89-I I3, jun. 2011.

MENDES, C. S. Análise das condições de acessibilidade em equipamentos públicos educacionais no município de Passos - MG. Dissertação (Mestrado em Planejamento e Análise de Políticas Pública) - UNESP, Franca, 2018.

NUNES, D. R. DE P. Necessidades Educacionais Especiais: Do que estamos falando? Revista Educação em Questão, v. 3 I, n. 17, p. I-II, 2008. Disponível em: http://arquivos.info.ufrn.br/arquivos/20I I I 97202be9c62 I482d I 2cc0 I4168a/nee_do_que_estamos_fal ando_debora_nunes.pdf. Acesso em: 22 fev. 2021.

OLIVEIRA, R. P. de; ARAUJO, G. C. de. Qualidade do ensino: uma nova dimensão da luta pelo direito à educação. Revista Brasileira de Educação, n. 28, p. 5-23, 2005. Disponível em: http://www.scielo.br/scielo.php?script=sci_arttext\&pid=SI 4 | 3-24782005000 $100002 \&$ lng=pt\&tlng=pt. Acesso em: 4 ago. 2018.

PINHAIS. Lei n 1.059 de 28 de dezembro de 2009. Dispõe sobre o Plano Municipal de Educação. 2009. Disponível em: http://www.jusbrasil.com.br/legislacao/863/6I/lei-1059-09-pinhais. Acesso em: 8 set. 2020.

SCHNEIDER, G.; GOUVEIA, A. B. Qualidade de escola: uma proposta de índice para as condições materiais de escolas a partir de dados contextuais do Saeb. Revista Brasileira de Pós-graduação, v. 8, n. supl.I, p. 59-82, 20I I. Disponível em: http://ojs.rbpg.capes.gov.br/index.php/rbpg/article/view/236/226. Acesso em: 5 jun. 202I. 
XIMENES, S. B. O Conteúdo Jurídico do Princípio Constitucional da Garantia de Padrão de Qualidade do Ensino: uma contribuição desde a teoria dos direitos fundamentais. Educação \& Sociedade, v. 35, n. 129, p. 1027-1051, 2014. Disponível em:

http://www.scielo.br/scielo.php?script=sci_arttext\&pid=SO I $01-73302014000401027 \&|n g=p t \& t| n g=p t$. Acesso em: 22 mar. 202I.

Recebido em: 08 de julho de 2021 .

Versão corrigida recebida em: 23 de agosto de 2021.

Aceito em: 23 de agosto de 2021 .

Publicado online em: 26 de novembro de 2021 .

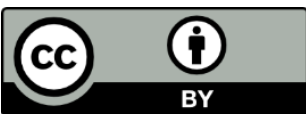

